\title{
DYNAMIC RESPONSE OF PREFABRICATED BUILDING UNDER SEISMIC LOADING
}

\author{
B. Hema Sumanth \\ School of Mechanical and Building Sciences \\ VIT, Chennai, Tamil Nadu, India
}

\begin{abstract}
There are many new technologies arriving in the field of construction, one of those is prefabricated buildings which means the components or structural members of the building are cast in the factory and then fixed in the site. Although the technology developed many years back, in India, the implementation is improving in these days only. It is important to study the prefabricated building performance under seismic loading because the behavior of prefabricated concrete building is entirely different from the normal building. So, in the present investigation, a $G+7$ storey prefabricated building was taken into consideration to check the behavior and performance. The modeling of the building was done using TEKLA software and then it is analyzed using ETABS for the response spectrum analysis.
\end{abstract}

Keywords - Prefabrication, Residential Building, Response spectrum, Dynamic analysis

\section{INTRODUCTION}

Due to the rapid growth of development in India, there is much scope for the prefabrication. The major cities in India like Mumbai, Chennai, Delhi, Calcutta, and Bangalore have already prefabricated buildings and bridges. Not only in India throughout the world it has been already improved and also using vastly but the Precast concrete development was not utilized in enormous scale in business and private ventures because of numerous issues the real disadvantages were, Lack of standard rules by structure experts and Complicated examination plan methodology, which was impractical without progression of computer application in investigation and structure [1]. Introduction of lifting equipment and transportation equipment. Improvement in solid innovation additionally required quality and mechanical properties can be accomplished effectively in solid now daily[2]. Progression in association system to gather precast segment like post focusing on, dowel association, steel grapple associations and so on. The cons of this system are Improved quality control can be kept up in the modern generation. Better indoor working condition to cast precast segments [3]. The deficiency of on location talented specialists is unraveled by precast

\author{
K. Vasugi \\ School of Mechanical and Building Sciences \\ VIT, Chennai, Tamil Nadu, India
}

development. The precast parts are thrown in exact steel shape henceforth on location formwork isn't required[4]. Financially savvy creation because of cost decrease from formwork, platform. It is raised effectively without tremendous time hole for relieving, formwork, fortification creation on location. Thin individuals like T-segment and I-segment can be created to satisfy the engineering need and material sparing[5]. Transportation cost is diminished when the venture site is in affordable reach. Yet, the significant trouble looked by auxiliary specialists in executing this system in huge scale venture since its seismic exhibition was not acceptable which significantly rely upon association type used to interface one part with other and absence of solidifying components for even stiffness of structure with shear walls and core walls[6]. X.C. Liu et.al.(2017) [7]. The plan and development of a secluded, pre-assembled, multi skyscraper structure are institutionalized and modularized. The modules are made in the production line and are quickly amassed with jolts nearby. This structure has the upsides of quick development, lower workforce, and decreased development contamination, which has a place with ecologically well-disposed structure rehearses. Presently, modularized steel structures are fundamentally connected in low-ascent structures with developing systems; in any case, they are seldom connected to elevated structure structures. Ai-Lin Zhang et.al.(2019) [8]. has taken five examples were structured, and the low-cycle responding test and numerical reproduction were completed on these specimens and the comparing fixed examples. The parameters, for example, the types of rib spread plates, the types of associating plates, the center jolts interim and the impact of the quake versatile conduct on the mechanical properties of the joints are explored, and the heap relocation bends, skeleton bends and harm models of every example are gotten. Ximei Zhai et.al.(2015) [9]. Has taken Six twofold short-appendage fortified cement (RC) pre-assembled shear dividers with various infill divider were built and tried under cyclic even burden and consistent vertical burden to think about the seismic performance, including unfilled shear divider, ceramsite solid empty square stonework infilling, concrete integration infilling with empty cylinder (HTCI), solid reconciliation infilling with polystyrene plate sandwich (PPSCI), lightweight parcel board infilling and ceramsite concrete infilling 


\section{International Journal of Engineering Applied Sciences and Technology, 2019 Vol. 4, Issue 8, ISSN No. 2455-2143, Pages 374-377 \\ Published Online December 2019 in IJEAST (http://www.ijeast.com)}

\section{A. Response Spectrum Analysis}

Response spectra curves plotted between the most extreme reaction of SDOF framework exposed to determined quake ground movement and its timespan (or recurrence). Reaction range can be translated as the locus of the greatest reaction of an SDOF framework for given damping proportion. Reaction spectra subsequently help in getting the peak auxiliary reactions under straight range, which can be utilized for acquiring parallel powers created in structure because of seismic tremor consequently encourages in the quake-safe plan of structures. Typically, the reaction of an SDOF framework is controlled by time space or recurrence area examination, and for a given timeframe of the framework, the greatest reaction is picked. This procedure has proceeded for all scope of conceivable timeframes of SDOF framework. Last plot with framework timespan on $\mathrm{x}$-axis and reaction amount on the $y$-axis is the required reaction spectra relating to indicated damping proportion and information ground movement. The same procedure is completed with various damping proportions to get general response spectra.

\section{ANALYTICAL INVESTIGATION}

A G+7 storey prefabricated building was considered in the present study with various prefabricated elements like pad footing, beams, columns, slab, joint connections. And prefabricated building modeling can be done using computer applications like REVIT and TEKLA.

In this investigation, it is done using TEKLA (a building information modeling software). The building specifications used in the modeling were given in Table 1 and an asymmetrical plan has taken for the study and it is given in Fig. 1 and Fig. 2 represents the 3D model of the building and Fig. 3 represents the beam-column joint with concrete corbel connection for the building

Table -1 Building specification used in the modeling

\begin{tabular}{ccc}
\hline Component & Material & Specification $(\mathbf{m m})$ \\
\hline Beam & $\mathrm{C25} / 30$ & $250 \times 300$ \\
\hline Column & $\mathrm{C35} / 40$ & $400 \times 400$ \\
\hline Slab & $\mathrm{C50/60}$ & 200 \\
\hline Foundation & $\mathrm{C50/60}$ & $\mathbf{1 8 0 0 \times 1 8 0 0}$ \\
\hline
\end{tabular}

Table -2 specification used for Analysis

\begin{tabular}{cc}
\hline Zone & IV \\
\hline Soil type & Type-II soil \\
\hline Seismic zone factor & 0.24 \\
\hline Response reduction factor & 5.0 \\
\hline Importance factor & 1.5 \\
\hline
\end{tabular}

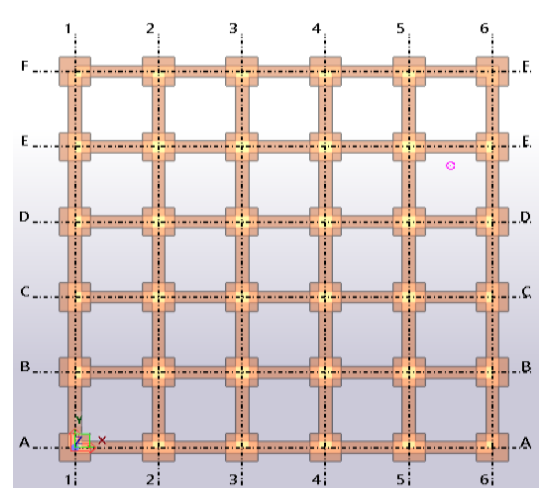

Fig. 1. Foundation Layout for G+7 storey

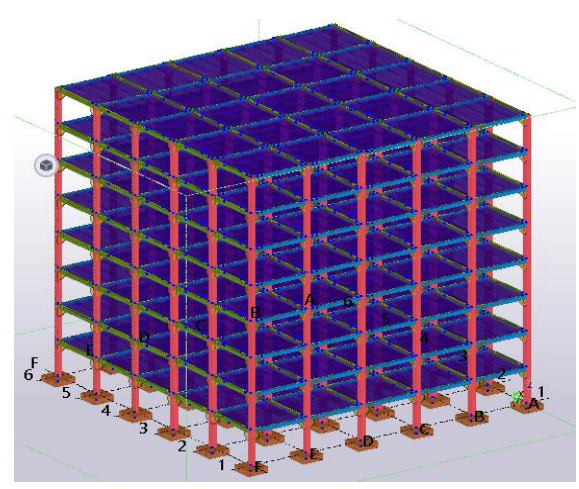

Fig. 2. 3D Modeling of G+7 storey

The building plan consist of 5bay in both $\mathrm{X}$ and $\mathrm{Y}$ direction with a spacing of $4 \mathrm{~m}$. and height betweentwo storey's is $3 \mathrm{~m}$ and height below the ground is taken as $1.5 \mathrm{~m}$. In any type of structure joints are the typical points in which possible failure may happen. So, in the prefabricated building also joints are the major components which are connected by various connections like concrete corbel, concrete console, etc. in the present study concrete corbel joint is used for the connections. And we can also see the prefabricated slab which is having hollow sections and a thickness of $200 \mathrm{~mm}$. Choosing a suitable type of foundation is very important for the life span of the building. because it has to transfer the structure load to the ground in this study pad foundation is used in the modeling. And live load is taken as $3 \mathrm{kN} / \mathrm{m}^{2}$. For the seismic analysis, the TEKLA model is imported into ETABS 


\section{International Journal of Engineering Applied Sciences and Technology, 2019 \\ Vol. 4, Issue 8, ISSN No. 2455-2143, Pages 374-377 \\ Published Online December 2019 in IJEAST (http://www.ijeast.com)}

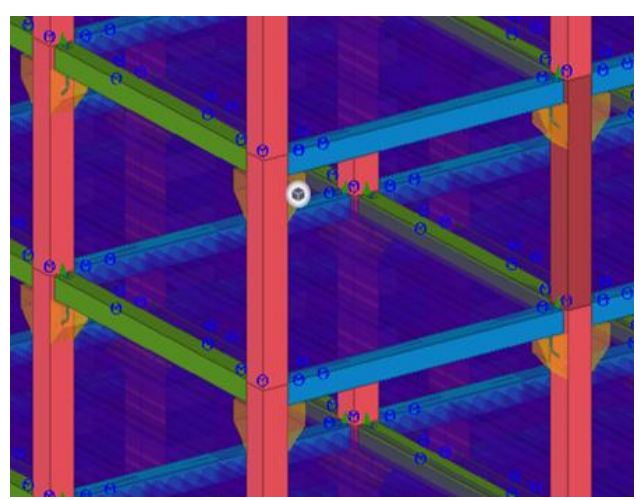

Fig. 3. Beam-Column Joint

After importing the G+7 storey model into the ETABS software the joints are assigned for Rigidity connection for the joints and the diaphragm for the building are created by selecting the beams, columns and joints. Response Spectrum analysis for the diaphragmed building is carried out according to the IS1893 (part-1):2016, Table 2 represents the factors are considered for the response spectrum analysis.

Table -2 Modal periods and Frequencies

\begin{tabular}{ccccc}
\hline Mode & $\begin{array}{c}\text { Period } \\
(\mathbf{s e c})\end{array}$ & $\begin{array}{c}\text { Frequency } \\
(\text { cyc/sec })\end{array}$ & $\begin{array}{c}\text { Circular } \\
\text { frequency }\end{array}$ & $\begin{array}{c}\text { Eigen value } \\
(\text { rad2/sec2 })\end{array}$ \\
\hline 1 & 1.076 & 0.92 & 5.837 & 34.10 \\
\hline 2 & 1.076 & 0.93 & 5.840 & 34.90 \\
\hline 3 & 0.925 & 1.08 & 6.795 & 46.17 \\
\hline
\end{tabular}

The time period taken for the different types of modes with frequencies and eigenvalues given in Table 3 . We can observe the time period and frequency of mode 2 and mode 3 is the same. But the time period of mode 3 is reduced but the frequency is increased. So, we can say that frequency is increased with a decrease in the time period [10].

Table -3 Storey Drift

\begin{tabular}{ccc}
\hline Load Case/Comb & Directions & Drift \\
\hline Dead & X & 9E-06 \\
\hline Dead & Y & 9E-06 \\
\hline Live & X & $\mathbf{0 . 0 0 1 0 8}$ \\
\hline Live & Y & $\mathbf{0 . 0 0 1 0 8}$ \\
\hline EQ 1 & X & $\mathbf{0 . 0 0 1 0 9}$ \\
\hline EQ 2 & Y & $\mathbf{0 . 0 0 1 0 9}$ \\
\hline EQ 3 & X & $\mathbf{0 . 0 0 1 1 9}$ \\
\hline EQ 4 & Y & $\mathbf{0 . 0 0 1 2 0}$ \\
\hline EQ 5 & X & $\mathbf{0 . 0 0 1 2 1}$ \\
\hline EQ 6 & Y & $\mathbf{0 . 0 0 1 2 0}$ \\
\hline
\end{tabular}

Table 4 represents the storey drift for the top storey both in $\mathrm{x}$ and $y$ directions. Actually, storey drift is the difference of displacements between two consecutive stories divided by the height of that story. Story displacement is the absolute value of displacement of the storey under the action of the lateral forces. For the various load cases, the storey drift will changes, from the table 4 for the dead load case the drift is same in both $\mathrm{x}$ and $\mathrm{y}$ directions and also for EQ 1 and EQ 2 case also almost storey drift is equal. Comparing the storey drift in Table 4 and maximum displacement in Table 5. we can say that as the lateral displacement increases, storey drift will also increases[11].

Table -5 Maximum Storey Displacement

\begin{tabular}{ccc}
\hline Load Case/Comb & Directions & Maximum $(\mathbf{m m})$ \\
\hline Dead & X & 0.208 \\
\hline Dead & Y & 0.217 \\
\hline Live & X & 2.635 \\
\hline Live & Y & 2.575 \\
\hline EQ 1 & X & 26.365 \\
\hline EQ 2 & Y & 26.168 \\
\hline EQ 3 & X & 28.739 \\
\hline EQ 4 & Y & 28.941 \\
\hline EQ 5 & X & 29.137 \\
\hline EQ 6 & Y & 28.941 \\
\hline
\end{tabular}

Table 5 represents the top storey maximum and average displacement. As in the prefabricated building, the joints are connected by corbel connection. So, these are stiff so that if the lateral force acting on the building them the whole building will displace more than a normal building. we can see the displacement with different load cases. If we compare all load cases in X-direction displacement is increased from 26.365 to $28.735 \mathrm{~mm}$ and from 28.735 to $29.137 \mathrm{~mm}$ and in $\mathrm{Y}$ direction also same.

Table -6 Base Reactions

\begin{tabular}{ccc}
\hline $\begin{array}{c}\text { Load } \\
\text { Case/Comb }\end{array}$ & FY(KN) & MZ $(\mathbf{k N}-\mathbf{m})$ \\
\hline Dead & 2.735 & -193.773 \\
\hline Live & 5.246 & -242.695 \\
\hline EQ 1 & 0 & 36188.55 \\
\hline EQ 2 & -2916.08 & -36451.04 \\
\hline EQ 3 & 0 & 39792.368 \\
\hline EQ 4 & -2916.08 & -40055.238 \\
\hline EQ 5 & 0 & 32584.750 \\
\hline EQ 6 & -2916.08 & -32846.85 \\
\hline
\end{tabular}

Table 6 represents the base reactions or the support reactions from the base of the building. response spectrum base reactions will differ from the sum of the individual reactions because their formulations differ [12]. Base reactions are calculated for each mode before modes are combined using the CQC or SRSS modal-combination rule. Joint reactions, on the other hand, are calculated using modal combinations which are applied to each individual joint. In table 6 in load cases EQ1, EQ 3, EQ 5 the horizontal reaction is same and as well as in the vertical reaction in EQ 2, EQ 4, EQ 6 is same and the moment 


\section{International Journal of Engineering Applied Sciences and Technology, 2019 \\ Vol. 4, Issue 8, ISSN No. 2455-2143, Pages 374-377 \\ Published Online December 2019 in IJEAST (http://www.ijeast.com)}

in the z-direction is different. For the load case, EQ 3 has a large moment that means in the $\mathrm{X}$ direction.

\section{CONCLUSION}

The behavior and response of the prefabricated G+7 storey building under seismic loading were investigated in this paper. From all the results obtained the below conclusions are made. Time Period for the mode shape 1 and mode shape 2 is same i.e. 1.076 and the Storey Drift is more in the load case EQ-5 and also the storey Maximum displacement is $29.137 \mathrm{~mm}$ in the load case EQ-5. Which shows that if the lateral displacement is increased then the storey drift will also increase. The storey drift will be more in the prefabricated building than in the normal monolithic building and the base reaction is more for the dead weight combination in $\mathrm{Z}$ direction i.e. $3257 \mathrm{kN}$ and for live load $5245 \mathrm{kN}$ Generally, for a normal building, it will be less.

\section{REFERENCE}

[1] Shen. Q and Meng. X. (2017). The Testing Research on Prefabricated Building Indoor Thermal Environment of Earthquake Disaster Region, Procedia Eng., vol. 205, pp. (453-460).

[2] Ding. P and Shi. C.(2019). Three-dimensional dynamic response analysis of a single-ring structure in a prefabricated subway station, Sustain. Cities Soc., vol. 45, pp. (271-286).

[3] Bernardini. C and Vignoli. A.(2019). The seismic performance-based assessment of a masonry building enclosed in aggregate in Faro (Portugal) by means of a new target structural unit approach, Eng. Struct., vol. 191, pp. (386-400).

[4] Jang. S and Lee.G.(2018). Process, productivity, and economic analyses of BIM-based multi-trade prefabrication-A case study," Autom. Constr., vol. 89, pp. (86-98).

[5] Hao.Y and Gang. S.(2018). Finite element analysis on the seismic behaviour of fully prefabricated steel structures,Eng. Struct., vol. 173, pp. (28-51).

[6] Li. H and Hao. H.(2019). Dynamic response of precast concrete beam with wet connection subjected to impact loads,Eng. Struct., vol. 191, pp. (247-263).
[7] Liu. X. et al.(2017). Seismic performance of H-section beam to HSS column connection in prefabricated structures,J. Constr. Steel Res., vol. 138, pp. (1-16).

[8] Zhang. A.L and Zhang. H.(2019). Experimental study of earthquake-resilient prefabricated steel beam-column joints with different connection forms, Eng. Struct., vol. 187, pp. (299-313).

[9] Shivacharan. K and Karthik N M.(2015). Analysis of outrigger system for vertical irregular system subjected to lateral loads, Vol.4, pp. (217-221)

[10] Zhai. X and Hu. X.(2019). Study on seismic performance of precast fabricated RC shear wall with opening filling, Constr. Build. Mater., vol. 214, pp. (539-556).

[11] Subramani. T and Kavitha .M.(2014). Earthquake analysis of structure by base isolation technique in SAP, Eng. Struct., vol. 4(296-305).

[12] Chavan. K. R and Jadhav. H.S.(2014). Seismic Response of R C Building With Different Arrangement of Steel Bracing System, vol. 4, pp. (218-222). 